\title{
9 Assistive robots in care: Expectations and perceptions of older people
}

Julia A. Hoppe, Rose-Marie Johansson-Pajala, Christine Gustafsson, Helinä Melkas, Outi Tuisku, Satu Pekkarinen, Lea Hennala, Kirsten Thommes

\section{Abstract}

This chapter analyzes older people's expectations and perceptions about welfare technology and in particular about robots in elderly care. Assistive robots may serve as a means to prolonged autonomy in old age as well as support for nursing staff. Justified by a rapid change in the health care sector, the need to focus on user driven and not technology driven development of assistive robots must be emphasized to ensure an adequate and sustainable orientation process toward assistive robots. This study presents an inventory of the expectations and perceptions of older people regarding assistive robots, by conducting a qualitative approach with focus group discussions. Our findings reveal that seven themes in particular need to be addressed in order to improve older people's perceptions of robot technology: (1) independence and safety, (2) physical and mental assistance, (3) communication and socialization, (4) relief to nursing staff, (5) individual's right to decide, (6) data protection, and (7) liability. Additionally, the focus group interviews stress that dissemination of information on how robots can provide assistance may change older people's attitudes towards technology.

\subsection{Introduction}

The importance of the topic of utilizing robots in welfare services refers to the rapid digitalization, as well as technology development of the health and welfare sector. The discussion is mainly technology driven, and less driven by needs of users (Östlund et al. 2015). The need for more research on robots in elderly care becomes apparent when looking at the contemporary trends in industrialized societies, characterized by an aging population, rising care costs and a decrease in qualified employees (Neven 2010; Sparrow and Sparrow 2006). These challenges need an innovative approach in welfare technology, which lies predominantly in the new organization of health care, for example by integrating assistive robots into the existing health care structures (Miskelly 2001). New areas are emerging in which technology is being applied in elderly care, for example in private homes as well as in providing new functions like social incentives and entertainment, video-monitoring, electronic sensors, remote health monitoring and equipment such as fall detectors (Nordic Centre for Welfare and Social Issues 2010).

Harrefors, Sävenstedt and Axelsson (2009) indicate that the new technology strategy broadens the possibilities of older people to be more independent, for exam- 
How would you feel having a robot to provide you service and companionship when infirm or old?

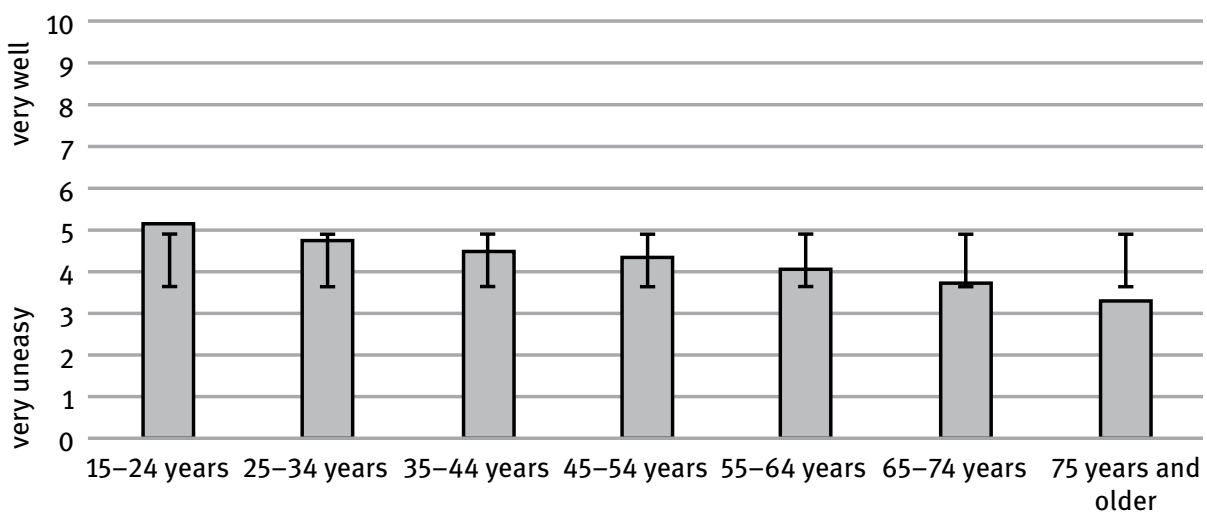

Fig. 9.1: European attitudes toward assistive robots by age groups (Mean).

ple by prolonging life in their familiar environment or by enabling remote communication with caregivers or family doctors from their homes. They state that one major problem that impedes the implementation of robots in elderly care is the population's fear towards robots in care in general and older people's fear in particular (see also Nomura, Kanda and Suzuki 2006).

The recent Eurobarometer (2017), for instance, reveals that younger people tend to be more open-minded with regard to assistive robots than older people, but still are unsure. People also tend to get more skeptical with more life years (European Commission and European Parliament 2017) (fig. 9.1).

Moreover, the Eurobarometer (2017) shows significant gender differences in peoples' attitudes towards robots. Fig. 9.2 illustrates that the attitudes towards assistive robots among Europeans are more negative among women than among men (European Commission and European Parliament 2017). Given that women have a higher life expectancy than men, this will aggravate the need for effective orientation. The result of the gender gap is attributed to technology related fears. While women express more negative emotions towards assistive technology (Hohenberger, Spörrle and Welpe 2016), men associate more positive emotions with automated systems, although both women and men show a slight increase in the proportion of negative attitudes over time. However, the proportion of women and men who indicate very positive and rather positive attitudes towards robots always predominates (European Commission and European Parliament 2017) (fig. 9.2).

Thus, the orientation of older people towards robotic care needs to be understood. Assistive robots in this context encompass any electronic device, partially or completely autonomous, that takes on care or assistive activities for people in need of help (Goeldner, Herstatt and Tietze 2015). The definition of assistive robots in this 


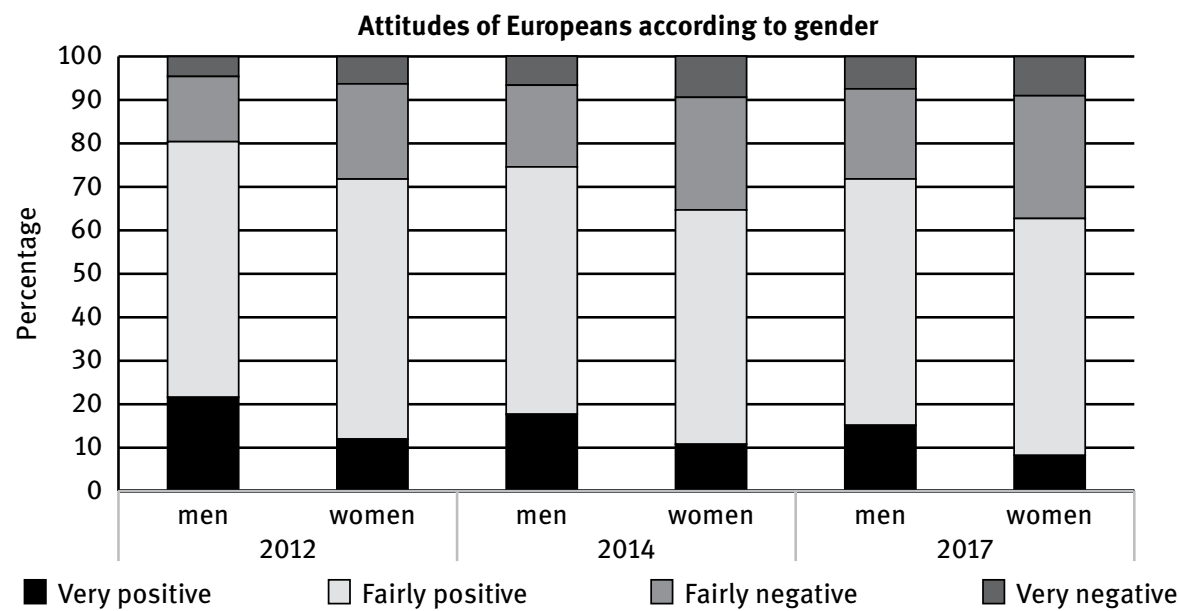

Fig. 9.2: Attitudes of Europeans according to gender.

study refers to the support of older people and care staff with emotional, cognitive and physical tasks (Glende et al. 2016).

In this paper, we explore older people's perceptions and attitudes regarding robotic care in Finland, Sweden and Germany by organizing focus group discussions with older people as participants. There are several aspects to examine, including how older people imagine their life when getting older and needing help in their daily lives, and how welfare technology and especially assistive robots could be a part of these (home) care services.

The remainder of our paper is as follows: First, we briefly review assistive robots in elderly care. Second, we discuss the problems, needs and challenges of assistive robots. Third, we present our method and show which themes are the most important for older people regarding their perceptions and expectations of assistive robots in future life. Finally, we discuss our findings and conclude.

\subsection{Contemporary demographic and technological development}

In a few years, the relative population of older people in Western Europe will rise due to the aging population as well as increasing life expectancy. In approximately 30 years, there will be more people in the world over the age of 60 than under the age of 15. When focusing on elderly care, a gigantic shift in technology must be proceeded to meet the societal demographic challenges (United Nations Department of Economic and Social Affairs, Population Division 2015; United Nations World Population Prospects 2015). Currently, due to economic and social mobility, more people live alone and far away from their families and relatives, implying that family care is not 
available. However, current developments in technology may contribute to mitigate the problems ahead, but along with technological challenges, societal resistance also needs to be understood to explore the opportunities and limits of technology assistance in elderly care.

In this context, this paper focuses on the contribution to efficient care services by examining the authentic needs of stakeholders to provide orientation towards welfare technology. These orientation themes should support older people in deciding about robotic care as well as other stakeholders by exploring contemporary needs and emotions of older people. Orientation is fundamental with regard to a successful implementation of such assistive welfare technologies in care services (Acatech and Körber-Stiftung 2018; ZEW 2012).

\subsubsection{Robots in elderly care - a brief review}

Socially assistive robots (SAR) can be distinguished into two main categories according to Kachouie et al. (2014): rehabilitation robots and assistive social robots, which can again be subdivided into companion robots and service robots (fig. 9.3).

Rehabilitation robots focus on physically assistive features to maintain and increase mobility. Furthermore, they are designed to support regaining diverging physical characteristics, such as muscular strength and flexibility. One example is the Exoskeleton, a smart robot system aimed at enhancing gait performance and daily activities (Lee et al. 2017; Sale et al. 2012). Besides their rehabilitation purpose, these robots are designed to facilitate tasks at home, for instance lifting and transporting objects (Huo et al. 2016).

Companion robots, often resembling animals or human bodies, are designed to improve older people's lives by increasing health and psychological well-being as well as decreasing loneliness (Fischinger et al. 2016). Dautenhahn, Campbell and Syrda (2015, p. 1) note that the role of companion robots is characterized by "both long-term and repeated interaction". Additionally, these robots can be used to facilitate social interactions with others. The JustoCat, a companion robot specifically developed for dementia patients, acts like a cat, is capable of reacting to being stroked and supports staff regarding remembrance (Abdi et al. 2018; Gustafsson, Svanberg and Müllersdorf 2016). Companion robots can also be used for persons without dementia. With respect to their functionality, they serve as entertainment purposes. One prominent example is the robot Zora, which stimulates exercising and leads to reminiscing because of its child-like character (Melkas et al. 2016).

Conversely, service robots are aimed at facilitating elementary activities, including eating, bathing or housework as well as supporting mobility, monitoring of people and maintaining safety (Kachouie et al. 2014). Although the spectrum of users' requirements in the field of housekeeping or physical support for daily tasks is broad (García-Soler et al. 2018), there are rarely any service robots available. During the re- 


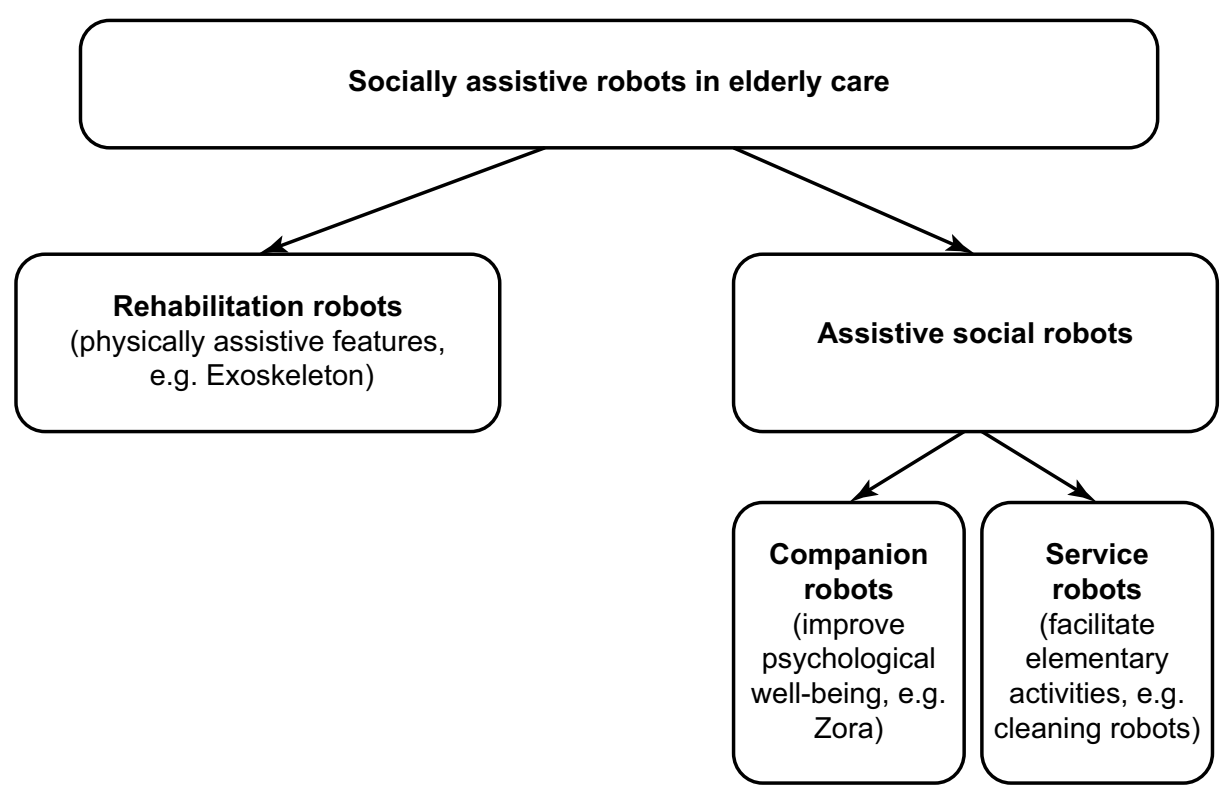

Fig. 9.3: Assistive robots in elderly care.

search there were little to no service robots especially targeted at tasks of daily living. Currently, cleaning robots such as vacuum robots are widely available for households, but robots that facilitate personal hygiene are still lacking (Kachouie et al. 2014).

Another crucial area to prolong the independent life of the older people is fall detection (Webster and Celik 2014). New technologies eliminate former deficiencies, including older people being incapable of using safety-alarm buttons in the case of falling or forgetting to wear support devices (Bajones et al. 2018).

\subsubsection{Meeting problems, needs and challenges of robots in elderly care}

The problems and challenges concerning the use of robots in elderly care can involve ethical issues as well as technological obstacles that need to be overcome in the future. As an example, Huo et al. (2016) conclude that, on top of the optimization of already existing exoskeletons' accuracy, one vital obstacle to overcome in the future is the development of more portable robots of higher efficiencies. Bedaf, Gelderblom and De Witte (2015, p. 97) state that the use of robot systems is questionable for any fields of elderly care "which do not require physical movement and/or force exertion". The authors predict that these robots, solely offering non-physical assistance like reminders, monitoring or fall detection, will not succeed in extending older people's independent living, but rather physical support is crucial for this aim (Bedaf, 
Gelderblom and De Witte 2015). The handling of fragile patients as one example of physical support is one of the next hurdles to overcome in the upcoming years of development of robot assistance systems. This is especially applicable for the category of service robots.

Besides technical difficulties in the field of robots in elderly care, legal, financial and safety concerns arise (Goeldner, Herstatt and Tietze 2015). One additional major problem that still hinders the successful use of robots in elderly care is the fact that many people are reluctant towards the idea of robot service or companionship. Looking at Europe, half of the population feels uneasy with the thought of robots in elderly care (Niemelä, Määttä and Ylikauppila 2016). One reason might be that older people are not efficiently integrated into the development process of new technologies (Östlund et al. 2015). The research of Compagna and Kohlbacher (2015, p. 20) clarifies the engineers' view towards older people as

"a weak and deficient user group [...] go[ing] hand in hand with a stereotypical and prejudiced view of older people that leads to a distorted way of including them in the development process. Developers may therefore not be able to grasp and appreciate the real meaning and value of older users' assessments of the new technologies and thus lead to non-desirable results".

Moreover, there is often an imbalance between perceptions of older peoples' technology needs and knowledge about their actual needs. The supposed user employs the technology according to the manufacturer's idea of how the item should be used. However, this is distinct from the real user, who is actually using the technology, and may for instance change the purpose of the technology (Dekker 2015). If diversity in users is incorporated at all, it is most often based on basic social distinctions such as age and gender differences (Flandorfer 2012). However, communication on equal levels and users' participation in the development process could decrease users' resistance. Vandemeulebroucke, de Casterlé and Gastmans (2018) suggest "democratic spaces" - spaces where stakeholders of elderly care can interact - as a way of overcoming existing boundaries between the different parties as well as the technology, to establish a shared vocabulary and, finally, accomplish a new view on robots in elderly care.

Bajones et al. (2018, p. 2) sum up, that "one of the biggest challenges is offering sufficient useful and social functionalities in an autonomous and safe manner to achieve the ultimate goal of prolonging independent living at home”. This goal can only be achieved as soon as the new technology is accepted by the individual users and the society at large. Therefore, it is of great importance to involve the future users of assistive robots in the developing and implementation process. If these processes are planned carefully, older people can benefit from assistive technology by means of promotion and improvement of health (Herstatt, Kohlbacher and Bauer 2011). However, there is a lack of useful indicators of good social technology solutions for older people (Taipale 2014). Additionally, the most convincing argument to motivate older 
people or care staff to use any type of technology is the individual benefit. Frennert (2016) stresses that this process is self-enforcing: older people are motivated to learn more about robot assistances if the robot has already proven capability of being useful for their special needs. Therefore, initial assistive robots need to fit into the environment of care staff and older people and meet certain needs. Moreover, when considering the needs of today's and future older people there might be a change, with regard to acceptance of technology for social needs and the strong western cultural value of being independent, which might be an incentive of using robots in everyday life. Once this is achieved, assistive technology is no longer considered as a single island, but rather as a support of care to provide new types of services (Melkas 2011).

\subsection{Method}

\subsubsection{Design}

In order to explore the contemporary expectations and perceptions of older individuals towards assistive robots, we follow a qualitative approach according to Mayring (2003). We use focus group discussions (FGDs) which are particularly suited to the study of attitudes and perceptions as they increase the diversity of opinions in a group. In addition, interaction within the groups of like-minded people, in this study in the sense of people of the same age, can help to talk more openly about a topic and clarify their own attitudes in ways that would be less accessible in individual interviews (Kitzinger 1995; Krueger and Casey 2014). The FGDs were conducted by two female researchers in each considered country, one as a moderator and the other as an assistant moderator. The moderators of the FGDs were female professors from nursing, innovation and economic departments. They were held in the participants' native language.

\subsubsection{Participants, procedure and data analysis}

In this paper, we focus on the perspective of older people living at home, therefore a targeted sampling was used to recruit the participants in Sweden, Finland and Germany. They were acquired through oral and written enquiries (e. g. through cities' retirement organizations and political voluntary retirement groups who were informed by their group leader or through an information e-mail form the ORIENT research team). Inclusion criterium for the selection of these groups was a minimum age of 60 years. In total, 24 older people participated, with four to seven participants in each group. All of them were living self-determined in their familiar environment, not needing any home care services. The older people had an average age of 72 years, 10 of them had a university degree, 10 of them a vocational education, three a secondary 
school certificate and one finished elementary school. Eight participants were male; 16 participants were female.

The self-developed interview guide includes opening, introductory and transition questions, as well as key questions following the recommendations of Krueger and Casey (2014). The interview guide is developed from pre-existing literature on the orientation process of assistive care robots, notably based on Melkas et al. (2016) as well as Raappana, Rauma and Melkas (2007). This guide was important, since the consistency between the settings in the three countries can be assured as the FGDs were conducted in Sweden, Finland and Germany.

At the beginning of each FGD all participants were asked to sign an informed consent form and to provide background information about themselves. The moderator of the interview then informed the participants about the aim of the discussion. The discussion followed the interview guide (Krueger and Casey 2014), moving from general to more specific questions. First, the participants were asked to brainstorm about the use and need of assistive robots in elderly care. This was followed by transition questions regarding the use of robot technology. Next, a short video and pictures of various types of care robots were shown and their possible support were shortly explained to the older people. The key questions focused on the general level of knowledge of care robots and if as well as how they should be introduced in elderly care. The FGDs in the three countries took between 60-140 minutes and were audio recorded, and then transcribed verbatim and processed as texts. Moreover, the FGDs were conducted in each country's national language, but the transcriptions were translated to English. For the analysis of the FGDs we used an inductive coding following Gioia, Corley and Hamilton (2013) with a semantic approach (Braun and Clarke 2006). Thus the following themes were developed from the datasets of the FGDs. We used the semantic approach, because the themes are identified within the explicit or surface meanings of the data, which means that the researcher is not looking for anything beyond what a participant has said. The goal is to theorize the significance of the patterns and their broader meanings and implications (Braun and Clarke 2006). The transcribed text was read a few times by the researchers to find statements regarding the attitudes and expectations and perceptions of the older people towards assistive robots. Meaningful statements regarding attitudes, expectations and perceptions were marked and initial codes were generated through all FGDs. Afterwards, the codes of all three countries were grouped together and discussed until theoretical saturation. Seven topics concerning attitudes and expectations and perceptions have been created. 


\subsection{Results}

Table 9.1: Displays themes evolved in the FGDs.

\begin{tabular}{|c|c|}
\hline Theme & Example quote \\
\hline $\begin{array}{l}\text { (1) Independence and } \\
\text { safety }\end{array}$ & $\begin{array}{l}\text { - "I would accept a nursing robot if I started having trouble with moving } \\
\text { at home. So that it would be helping me to go to the toilet or to wash } \\
\text { myself. Of course it would never replace having a conversation. But I } \\
\text { would understand that it would be safer after all, if I had problems like } \\
\text { that" (FIN 2018). } \\
\text { - "So it's definitely going to produce security. If it wouldn't be there, you } \\
\text { were more insecure than if you know someone is there when I tumble } \\
\text { or can help me in case of emergency. This safety issue should not be } \\
\text { neglected" (GER 2018). }\end{array}$ \\
\hline $\begin{array}{l}\text { (2) Physical and men- } \\
\text { tal assistance }\end{array}$ & $\begin{array}{l}\text { - "I would also rather make use of an assistive robot than using a wheel- } \\
\text { chair. This would give me the opportunity to be mobile" (GER 2018). } \\
\text { _ "I might accept it at some point, if it picked up my garbage from the } \\
\text { floor. When I drop things, then I have to somehow try to pick them up } \\
\text { myself. In that regard I'd take it" (FIN 2018). }\end{array}$ \\
\hline $\begin{array}{l}\text { (3) Communication } \\
\text { and socialization }\end{array}$ & $\begin{array}{l}\text { - "The last one here [Furhat], for example: I can imagine that it is inter- } \\
\text { rupting loneliness. I live alone. There are days, where I don't speak to } \\
\text { anyone at all, if I don't call anyone. I don't necessarily feel lonely now, } \\
\text { but I am always happy when there is someone around who speaks. } \\
\text { Maybe in a way, it replaces my need for human contact” (GER 2018). } \\
\text { - "I don't know whether I could talk to a robot. [...] Of course I would hope } \\
\text { that someone would visit me in person" (FIN 2018). }\end{array}$ \\
\hline $\begin{array}{l}\text { (4) Relief to nursing } \\
\text { staff }\end{array}$ & $\begin{array}{l}\text { - "I think that one of the first tasks will probably be to relieve the staff } \\
\text { of physically heavy work. Just something like lifting or, carrying" (GER } \\
\text { 2018). } \\
\text { _ "In my opinion, technology helps the caring staff, if they have good } \\
\text { equipment" (FIN 2018). }\end{array}$ \\
\hline $\begin{array}{l}\text { (5) Individual's right to } \\
\text { decide }\end{array}$ & $\begin{array}{l}\text { - "I can envision that older people can use robots without any problems. } \\
\text { But for dementia patients, I think it is shameful and inhuman to use } \\
\text { robots. I think that we should not use that in Germany" (GER 2018). } \\
\text { - "I think - yes, only if I can choose myself. Being able to say yes or no } \\
\text { thank you, that is very basic for me" (SWE 2018). }\end{array}$ \\
\hline (6) Data protection & $\begin{array}{l}\text { - "One aspect that certainly plays an important role is security, data se- } \\
\text { curity. Because these electronic things work via WIFI or similar things" } \\
\text { (GER 2018). } \\
\text { _- "About the legal aspects and data protection, that's probably a story, I } \\
\text { can't influence, probably a political decision will be necessary or courts } \\
\text { will have to decide what the robot may and may not do" (GER 2018). }\end{array}$ \\
\hline
\end{tabular}


Table 9.1: (continued) Displays themes evolved in the FGDs.

\begin{tabular}{ll}
\hline Theme & Example quote \\
\hline (7) Liability & "What happens if the robot makes a mistake, e. g. delivers the wrong \\
& medicine? Who is liable? Actually, it is obviously the caregivers in the \\
& case that they provide the wrong medicine. But if the robot gives a \\
& wrong drug, who is liable then?" (GER 2018). \\
- "Because the person who programs the algorithms cannot be held \\
responsible in the end [...] I believe that, as with autonomous driving, it \\
will ultimately be a legal issue to be solved" (GER 2018).
\end{tabular}

\subsubsection{Independence and safety}

The implementation of welfare technology in general, and in particular assistive robots in everyday life was perceived as a tool to support a prolonged independent life, which, from the point of view of older people, is associated with a higher degree of autonomy and integrity. Moreover, some imagine receiving support from a robot in hygiene, for instance in cases where nursing services are perceived as threatening integrity.

Of course, there are also older people who prefer the presence of human staff and reject the use of welfare technology. Another important aspect, when discussing support of assistive robots in everyday life, was the argument of safety. Older people perceived the tools of monitoring, saving health data (e. g. blood pressure and blood glucose), or the reminder function for medicines as added security.

\subsubsection{Physical and mental assistance}

Another aspect in which almost all participants have a common view, relates to the simplification of tasks throught the assistance of robots. Practical tasks like picking up things from the floor, cleaning the floor, as well as mobility supportive tasks were discussed as enormously useful in daily life. In addition, the support of people with cognitive impairments was also mentioned as a possible application area for assistive robots.

\subsubsection{Communication and socialization}

With regard to better communication, older people mentioned on the one hand shorter communication channels as beneficial, by using the tablet of an assistive robot to connect them with care staff or facilitate communication with relatives and on the 
other hand the increase of possibilities for their social life, for instance through entertainment and mental stimulation. However, there were also participants who perceived the monitoring function of an assistive robot as dangerous. The topic of conversation with assistive robots was also perceived differently in the groups. Some of the participants would prefer a conversation with a robot than having no conversation at all. Others cannot imagine communicating with robots. The participants also had divided opinions about social robots. Some thought that social assistive robots could reduce the feeling of loneliness, while others would not interact with social robots. A further concern was the fear of not being capable of handling assistive robots and the risk of becoming even lonelier.

\subsubsection{Relief to nursing staff}

The older people perceived assistive robots as a great advantage in supporting professional caregivers in daily standard tasks, as professional caregivers can invest more time in patients therefore human resources will only be used where they are really needed. The participants suggested that support of assistive robots is conceivable in the area of physically heavy work, personal cleaning, hygiene and service.

It was also mentioned that robots can be a good support in times of shortage of skilled workers. However, concerns were expressed whether assistive robots could also replace skilled workers. This consideration was based on the assumption of the older people that robots are in the long run probably cheaper than care staff. However, some participants in the FGDs argued against the fear of replacing care staff by robots, because robots cannot provide human warmth nor interpersonal relations or psychological support.

\subsubsection{Individual's right to decide}

A crucial theme in the orientation process of assistive robots are the regulations. Thereby a common view of the older people is that each user must have the right to decide whether to use assistive robots when getting older or not. There are different attitudes: some older people could imagine using robots later in life, others prefer assistance of human staff. Hence, the appropriate time in the estimation process of the individual situation is needed to find a convenient moment to give an orientation regarding assistive robots. Moreover, the use of assistive robots with regard to cognitive impaired people, like dementia patients was discussed. Some participants thought that dementia patients should be involved, while others would judge the use of assistive robots for dementia patients.

However, a few participants had the perception that there should not always be the possibility to choose, therefore some things should be established. 


\subsubsection{Data protection}

The theme of data protection mirrors different aspects of data protection when using an assistive robot. Many older people of the FGDs felt a great uncertainty, which should be solved through politics, as well as the law by setting legal limits and regulations. One important question was "Who can access any videos made by a robot, can the older people delete some sequences?” (GER 2018).

\subsubsection{Liability}

The FGDs with older people emphasized that liability must be legally defined and communicated as the older people were very insecure about this topic. Also, malfunctioning due to technical errors or power shortages were discussed heavily and the question of liability was a major obstacle to older people for using robots.

\subsection{Discussion}

During the FGDs, the different levels of knowledge of older people about welfare technology and especially assistive robots was determined. There were both positive and negative attitudes towards this topic. The negative attitudes did not refer to robots in general, but to robots in care in particular. This suggests that the use of robots in elderly care is not as accepted as in other areas of health care (European Commission 2015). With regard to the themes analyzed by the statements of the older people, it could be observed that the topic of data security was only addressed by the German participants and there were no mentions about liability in the Finnish statements.

However, with regard to the older people of the FGDs, a big change in attitudes was recognizable with the dissemination of information. Some indicated that they had a negative attitude towards assistive robots in care at the beginning of the group discussion. Qualitatively, men in the FGDs were notably more open to welfare technology in general and robotic technology in particular. However, this attitude changed over the course of the group discussion due to their increased level of information and a clearer understanding of what is meant by welfare technology, especially by assistive robots in elderly care and how it can be used to assist daily life. In addition, the tendency of the perceptions of almost all older people towards the use of robots in elderly care is much more positive. The results of these FGDs show that there is a general acceptance of assistive robots. However, a better orientation for the persons concerned is urgently required. This is in line with the results of Melkas et al. (2016) and applies above all to groups involved in the implementation processes in the field of elderly care, such as relatives and professional caregivers. This could be supported by storytelling of older people, relatives or care staff who had contact with such 
assistive technologies which at the same time could be a good method to get reliable information. Also the media which has an extensive range that could increase the dissemination of knowledge and information.

After discussing the themes generated through the FGDs, the interviewees were open to an implementation of selected technologies and could envision themselves as potential users. However, some important aspects should be considered for a successful implementation. One case that must be ensured with regard to the development and implementation of welfare technology is the improvement of daily life for older people and working life for caregivers and relatives. According to the perceptions from the FGDs, needs that can be improved by assistive robots refer to a higher autonomy, a certain safety and security through the presence of a robot as well as through the ability to independently manage daily life and improve working life. Our findings reflect the view that during the development and implementation of robots in elderly care the authentic needs of later users should be focused on (Gustafsson 2015). To ensure the authentic needs it is inevitable to involve end-users, older people, caregivers or relatives in the processes of welfare technology (Kristensson, Matthing and Johansson 2008). These users of welfare technology should ideally be involved in both the development process from the beginning as well as in the ongoing (Kristensson, Matthing and Johansson 2008; Elg et al. 2012).

Until July 2019, assistive robots were only prevalent in a few nursing homes except for some pilot projects with Zora or Pepper. Much more common were companion robots such as Paro (Wada et al. 2010) or JustoCat (Abdi et al. 2018; Gustafsson, Svanberg and Müllersdorf 2016). Other service and companion robots, as well as rehabilitation robots, just recently passed pilot studies.

\subsection{Conclusion}

The characteristics of assistive robots are different to other technologies in elderly care, especially as an emotional connection may arise. When investigating the implementation of robots with regard to the acceptance of society, different factors like social and hedonic ones must be considered, which are usually not included in technology acceptance models (Melkas et al. 2016; Parviainen et al. 2016). The structure of co-creation of assistive robots is different to other co-creation processes, because several people (relatives, caregiver) are involved in this process and not only the customer or in this case the older people. Of course, this also poses major challenges in comparison to other co-creations, but only if these stakeholders work together a comprehensive overview of technological opportunities and authentic needs can be ensured. As long as this cooperation does not have the same influence on the developmental processes, there cannot be a successful implementation of assistive robots in care. Additionally, Raappana, Rauma and Melkas (2007) researched the implementation of welfare technology and found that a good orientation (dissemination 
of knowledge, training and information before implementation) prevents the appearance of negative effects. This is based on the fact that without knowledge, training and information people would develop feelings of incapability and overcharging. This unilateral process of developing assistive robots impedes the implementation of robotics in care, whereby the integration of stakeholders would improve the implementation process by supporting authentic needs, as well as by reducing the fear towards the implementation of assistive robots in care (Harrefors, Sävenstedt and Axelsson 2009; Nomura, Kanda and Suzuki 2006).

Regardless of the country, the representatives of care should identify and communicate authentic needs in care, which could be solved by adding welfare technology and especially assistive robots. This would give care staff more time for tasks that really need human affection and could hand over simple auxiliary tasks to the robot to relieve nursing staff (United Nations Department of Economic and Social Affairs 2015; United Nations. World Population Prospects 2015). However, this does not solve the demographic problems; there are many other aspects that need to be considered in elderly care. For instance, the implementation of regulations to decide by themselves if assistive robots are wanted or not, as well as regulations for data protection and liability of assistive robots. Notably for data protection and liability, we found differences in the perceptions of older people, while the older people in the German FGDs discussed data security and liability in particular. The issue was not mentioned in the FGDs in Finland and Sweden. Therefore, future research should investigate why some issues are more pronounced in certain countries. The reasons may be attributed to different penetration of digitalization in different countries in general, different experiences or a different public discussion. Our FGDs also suggest that trust in the general health care system affects trust in innovations in the health care sector such as in assistive robots. The FGDs also indicated that financial responsibilities must be determined.

For the innovators it must be considered that older people of future generations have grown up with digitalization in contrast to today's generation (Porras et al. 2014). Therefore, the selection of stakeholders in the process of technology development should be considered carefully; it would not be enough to include only today's generation of older people.

Additionally, referring to the results of this study we can conclude that today's older people are open-minded with regard to welfare technology and especially assistive robots, provided that they have sufficient knowledge and information on how robots can support daily life. Nevertheless, there are also older people who cannot imagine being supported by robots and prefer human care even if they are sufficiently informed about assistive robots. 


\subsection{Acknowledgment and funding information}

This study was supported by the ORIENT project under the JTC 2017 launched by JPI MYBL. The support of the JPI MYBL and the national funders within the JPI MYBL framework is gratefully acknowledged (award no.16SV7954 by the Federal Ministry of Education and Research, Germany, award no. 2017-02300 by Forte, Sweden, and award no. 318837 by Academy of Finland).

\section{References}

Abdi, Jordan, Ahmed Al-Hindawi, Tiffany Ng and Marcela P Vizcaychipi. 2018. Scoping review on the use of socially assistive robot technology in elderly care. BMJ open

Acatech and Körber-Stiftung. 2018. TechnikRadar 2018. Was die Deutschen über Technik denken. https://www.acatech.de/wp-content/uploads/2018/05/Langfassung-Technikradar-Einzelseiten-final-1.pdf. Accessed 27 September 2018.

Bajones, Markus, Daniel Fischinger, Astrid Weiss, Daniel Wolf, Markus Vincze, Paloma de la Puente, Tobias Körtner, Markus Weninger, Konstantanios Papoutsakis, Damien Michel, Ammar Qammaz, Paschalis Panteleris, Michalis Foukarakis, Ilia Adami, Danai Ioannidi, Asterios Leonidis, Margherita Antona, Antonis Argyros, Peter Mayer, Paul Panek, Håkan Eftring and Susanne Frennert. 2018. 'Hobbit: Providing Fall Detection and Prevention for the Elderly in the Real World'. Journal of Robotics. https://doi.org/10.1155/2018/1754657

Bedaf, Sandra, Gert Jan Gelderblom and Luc de Witte. 2015. 'Overview and categorization of robots supporting independent living of older people: what activities do they support and how far have they developed. Assistive Technology'. The Official Journal of RESNA. https://doi. org/10.1080/1040 0435.2014.978916

Braun, Virginia and Victoria Clarke. 2008. 'Using thematic analysis in psychology'. Qualitative research in psychology. https://doi.org/10.1191/1478088706qp063oa

Compagna, Diego and Florian Kohlbacher. 2015. 'The limits of participatory technology development: the case of service robots in care facilities for older people.' Technological forecasting and social change. https://doi.org/10.1016/j.techfore.2014.07.012

Dautenhahn, Kerstin, Anne Campbell and Dag Sverre Syrda. 2015. 'Does anyone want to talk to me?: Reflections on the use of assistance and companion robots in care homes.' 4th International Symposium on New Frontiers in Human-Robot Interaction. The Society for the Study of Artificial Intelligence and the Simulation of Behaviour (AISB).

Dekker, Els. 2015. Robot Zora: Friend or Foe?: An Exploratory Study about the Emotional Attachment of Elderly to Robot Zora. http://arno.uva.nl/cgi/arno/show.cgi?fid=606146. Accessed 02 September 2018.

Elg, Mattias, Jon Engström, Lars Witell and Bozena Poksinska. 2012. Co-creation and learning in health-care service development. Journal of Service Management 23(3): 328-343.

European Commission. 2015. Special Eurobarometer 427: Autonomous systems. technical report. https://ec.europa.eu/commfrontoffice/publicopinion/archives/ebs/ebs_427_en.pdf. Accessed 22 November 2018.

European Commission and European Parliament. 2014. 'Eurobarometer 77.1 (2012): TNS Opinion \& Social [producer]'. GESIS Data Archive, Cologne. ZA5933 Data file Version 5.0.0, doi:10.4232/1.12265

European Commission and European Parliament. 2015. 'Eurobarometer 82.4 (2014). TNS Opinion [producer]'. GESIS Data Archive, Cologne. ZA5597 Data file Version 3.0.0, doi:10.4232/1.12014 
European Commission and European Parliament. 2017. 'Eurobarometer 87.1 (2017). TNS Opinion [producer]'. GESIS Data Archive, Cologne. ZA6861 Data file Version 1.2.0, doi:10.4232/1.12922

European Commission website. European Commission. http://ec.europa.eu/commfrontoffice/publicopinion/. Accessed 20 September 2018.

Fischinger, David, Peter Einramhof, Konstaninos Papoutsakis, Walter Wohlkinger, Peter Mayer, Paul Panek, Stefan Hofmann, Tobias Kortner, Astrid Weiss, Antonis Argyros and Markus Vincze. 2016. Hobbit, a care robot supporting independent living at home: First prototype and lessons learned. Robotics and Autonomous Systems 75: 60-78.

Flandorfer, Priska. 2012. 'Population ageing and socially assistive robots for elderly persons: the importance of sociodemographic factors for user acceptance'. International Journal of Population Research. http://dx.doi.org/10.1155/2012/829835 012

Frennert, Susanne. 2016. Older People Meet Robots: Three Case Studies on the Domestication of Robots in Everyday Life. Department of Design Sciences, Faculty of Engineering, Lund University. http://lup.lub.lu.se/search/ws/files/10672817/Final_version_Susanne_thesis.pdf. Accessed 03 September 2018.

García-Soler, Alvaro, David Facal, Unai Díaz-Orueta, Lucia Pigini, Lorenzo Blasi and Renxi Qiu. 2018. 'Inclusion of service robots in the daily lives of frail older users: A step-by-step definition procedure on users' requirements'. Archives of gerontology and geriatrics. https://doi.org/10.1016/j. archger.2017. 10.024 74, 191-196

Gioia, Dennis A., Corley, Kevin G. and Hamilton, Aimee L. 2013. Seeking qualitative rigor in inductive research: Notes on the Gioia methodology. Organizational research methods 16(1): 15-31.

Glende, Sebastian, Isabel Conrad, Livia Krezdorn, Susann Klemcke and Carola Krätzel. 2016. Increasing the acceptance of assistive robots for older people through marketing strategies based on stakeholder needs. International Journal of Social Robotics 8(3): 355-369.

Goeldner, Moritz, Cornelius Herstatt and Frank Tietze, F. 2015. 'The emergence of care robotics - A patent and publication analysis'. Technological Forecasting and Social Change. https://doi. org/10.1016/j. techfore.2014.09.005

Gustafsson, Christine. 2015. Utveckling och implementering av välfärdsteknologi inom demensvård. OMSORG Nordisk tidskrift för palliativ medisin 32(4): 26-30.

Gustafsson, Christine, Camilla Svanberg and Maria Müllersdorf. 2016. A robotic cat in dementia care-a pilot study. ISG 2016. World Conference of Gerontechnology 15: 151.

Harrefors, Christina, Stefan Sävenstedt and Karin Axelsson. 2009. 'Older people's perceptions of how they want to be cared for: an interview study with healthy elderly couples in Northern Sweden'. Scandinavian Journal of Caring Sciences. https://doi. org/10.1111/j.1471-6712.2008.00629.x

Herstatt, Cornelius, Florian Kohlbacher and Patrick Bauer. 2011. „Silver” Product Design: Product Development for older people. Institute for Technology and Innovation Management. Hamburg University of Technology. In Working Paper No. 65.

Hohenberger, Christoph, Matthias Spörrle and Isabell M. Welpe. 2016. 'How and why do men and women differ in their willingness to use automated cars? The influence of emotions across different age groups'. Transportation Research Part A: Policy and Practice. https://doi.org/10.1016/j. tra. 2016.09.022

Huo, Weiguang, Samer Mohammed, Juan C. Moreno and Yacine Amirat. 2016. Lower limb wearable robots for assistance and rehabilitation: A state of the art. IEEE systems Journal 10(3): 1068-1081.

Kachouie, Reza, Sima Sedighadeli, Rajiv Khosla and Mei-Tai Chu. 2014. 'Socially assistive robots in elderly care: a mixed-method systematic literature review'. International Journal of Human-Computer Interaction. https://doi.org/10.1080/10447318.2013.873278

Kitzinger, Jenny. 1995. Qualitative research: introducing focus groups. Bmj 311(7000): 299-302. 
Kristensson, Per, Jonas Matthing and Niklas Johansson. 2008. Key strategies for the successful involvement of customers in the co-creation of new technology-based services. International journal of service industry management 19(4): 474-491.

Krueger, Richard. A. and Mary Anne Casey. 2014. Focus groups: A practical guide for applied research. Sage publications.

Lee, Su-Hyune, Hwang-Jae Lee, Won-Hyuk Chang, Byung-Ok Choi, Jeonghun Kim, Guyu-Ha Ryu and Yun-Hee Kim. 2017. Gait performance and foot pressure distribution during wearable robot-assisted gait in elderly adults. Journal of neuroengineering and rehabilitation, 14(1): 123.

Mayring, Philipp. 2003. Qualitative Inhaltsanalyse. Basel: Beltz.

Melkas, Helinä. 2011. Effective gerontechnology use in elderly care work: From potholes to innovation opportunities. In the silver market phenomenon: Marketing and Innovation in the Aging Society, eds. Florian Kohlbacher, Cornelius Herstatt, 435-449. Berlin, Heidelberg: Springer.

Melkas, Helinä, Lea Hennala, Satu Pekkarinen and Ville Kyrki. 2016. Human impact assessment of robot implementation in Finnish elderly care. International Conference on Serviceology. 202-206.

Miskelly, Frank G. 2001. Assistive technology in elderly care. Age and ageing. https://doi.org/ 10.1093/ageing/30.6.455 0(6), 455-458.

Neven, Louis. 2010. 'But obviously not for me': robots, laboratories and the defiant identity of elder test users. Sociology of health \& illness. https://doi.org/10.1111/j.1467-9566.2009.01218.x, 32(2), 335-347.

Niemelä, Marketta, Hannamaija Määttä and Mari Ylikauppila. 2016. Expectations and experiences of adopting robots in elderly care in Finland: Perspectives of caregivers and decision-makers. ICServ 2016 Special Session: Meaningful Technologies for Seniors, 6(8.9).

Nomura, Tatsuya. Takayuki Kanda and Tomohiro Suzuki. 2006. Experimental investigation into influence of negative attitudes toward robots on human-robot interaction. Ai \& Society 20(2): 138-150.

Nordic Centre for Welfare and Social issues. 2010. Focus on welfare technology. https://nvc.brandfactory.se/Files/sv-SE/9047/RelatedFiles/Velferdsteknologi_eng.pdf. Accessed 26 September 2018.

Östlund, Britt, Elin Olander, Oskar Jonsson and Susanne Frennert. 2015. 'STS-inspired design to meet the challenges of modern aging. Welfare technology as a tool to promote user driven innovations or another way to keep older users hostage?' Technological Forecasting and Social Change, https://doi.org/10.1016/j.techfore.2014.04.012

Parviainen, Jaana, Lina van Aerschot, Tuomo Särkikoski, Satu Pekkarinen, Helina Melkas and Lea Hennala, L. 2016. 'Motions with Emotions? A double body perspective and human-robot interaction in elderly care'. International Research Conference Robophilosophy. IOS Press. http:// dx.doi.org/10.3233/978-1-61499-708-5-210

Porras, Jari, Kari Heikkinen, Marianne Kinnula, Lena Tolstrup Sørensen, Lea Hennala, Helina Melkas, Satu Pekkarinen and Nigel Jefferies. 2014. User 2020: A WWRF Vision.

Raappana, Anu, Marika Rauma Helinä Melkas. 2007. Impact of safety alarm systems on care personnel. Gerontechnology. 6(2): 112-117.

Sale, Patrizio, Marco Franceschini, Andreas Waldner and Stefan Hesse. 2012. Use of the robot assisted gait therapy in rehabilitation of patients with stroke and spinal cord injury. Eur J Phys Rehabil Med 48(1): 111-21.

Sparrow, Robert and Linda Sparrow. 2006. In the hands of machines? The future of aged care. Minds and Machines 16(2): 141-161.

Taipale, Vappu T. 2014. Global trends, policies and gerontechnology. Gerontechnology 12(4): 187-193. 
United Nations Department of Economic and Social Affairs, Population Division. 2015. World population ageing 2015. http://www.un.org/en/development/desa/population/publications/pdf/ ageing/WPA2015_Report.pdf. Accessed 26 June 2018.

United Nations. World Population prospects. 2015. http://esa.un.org/unpd/wpp/Publications/Files /WPP2015_Volume-I_Comprehensive-Tables.pdf. Accessed 30 July 2018.

Vandemeulebroucke, Tijs, Bernadette Dierckx de Casterlé and Chris Gastmans. 2018. 'How do older adults experience and perceive socially assistive robots in aged care: a systematic review of qualitative evidence'. Aging \& mental health. https://doi.org/10.1080/13607863.2017.1286455. 22(2): 149-167.

Wada, Kazuyoshi, Yousuke Ikeda, Kaoru Inoue and Recona Uehara. 2010. Development and preliminary evaluation of a caregiver's manual for robot therapy using the therapeutic seal robot Paro. In 19th International Symposium in Robot and Human Interactive Communication (pp. 533-538). IEEE. https://ieeexplore.ieee.org/stamp/stamp.jsp?tp=\&arnumber=5598615. Accessed 21 November 2018.

Webster, David and Ozkan Celik. 2014. Systematic review of Kinect applications in elderly care and stroke rehabilitation. Journal of neuroengineering and rehabilitation, 11(1): 108.

ZEW. 2019. Monitoring-Report: Digital Economy 2012 - Added Value for Germany. https://www. zew. de/en/publikationen/monitoring-report-digital-economy-2012-added-value-for-germany/. Accessed 29 November 2018. 